Black-White Differences in Beliefs about the U.S. Restaurant Tipping Norm: Moderated by Socio-Economic Status?

\author{
Michael Lynn \\ Cornell University \\ Jerome Williams \\ Rutgers University
}

Michael Lynn (WML3@Cornell.edu) is the Burton M. Sack Professor of Food and Beverage Management at the School of Hotel Administration, Cornell University, Ithaca, NY 1483-6902. Jerome Williams (jeromew@business.rutgers.edu) is the Prudential Chair in Business, Rutgers Business School - Newark, 1 Washington Park - Room 1040, Newark, NJ 07102.

International Journal of Hospitality Management (in press) 


\begin{abstract}
A re-analysis of two national telephone surveys found that black-white differences in awareness that it is customary to tip a percentage of the bill declined as socio-economic status increased. However, black-white differences in awareness that is customary to tip 15 to 20 percent in restaurants was unrelated to socio-economic status. The practical as well as theoretical implications of these findings are discussed along with directions for future research.
\end{abstract}

Keywords: race differences, socio-economic status, tipping 


\section{Black-White Differences in Beliefs about the U.S. Restaurant Tipping Norm: Moderated by Socio-Economic Status?}

In the United States, as well as in many other countries around the world, it is customary for consumers to leave voluntary sums of money (tips) for the service workers who have served them. Among the many service workers commonly tipped are bartenders, barbers, concierges, cruise cabin stewards, delivery drivers, doormen, exotic dancers, golf caddies, hotel maids, musicians, parking valets, porters, restaurant waiters, taxicab drivers, and tour guides (Star, 1988). Although the amounts given by a single customer to any one worker are typically modest, the total amount tipped to all workers is substantial with one estimate placing the annual tips to food workers in the United States a alone at over $\$ 40$ billion (Azar \& Tobol, 2008).

Tipping behavior is largely driven by social norms (Conlin, Lynn \& O’Donoghue, 2003) that vary across nations and sub-cultural groups within nations (Lynn, 2006a). For example, previous research has found that Blacks in the United States tip less than Whites in large part because they have different perceptions and beliefs about the customary or normative tip amount (Lynn, 2004, 2006b, 2011). In fact, approximately 70 percent of white adults in the U.S. believe that it is customary or normative to tip 15 to 20 percent of the bill size in restaurants while only about 35 percent of black adults in the U.S. hold this belief (Lynn, 2004, 2006b).

One issue not addressed in the current literature is whether or not this race difference in normative beliefs is moderated by socio-economic status. Researchers have convincingly demonstrated that SES is only a weak and partial mediator of race 
differences in beliefs about tipping norms (Lynn, 2004, 2006b), but no one has examined if and how SES might interact with race to affect beliefs about tipping norms. This gap in the literature deserves investigation because a long standing theory is that the more middle-class or bourgeois Blacks are, the weaker their ethnic or race commitment (Frazier, 1957). Early versions of this theory held that as middle-class Blacks move up the socio-economic ladder, they become more assimilated or integrated into the mainstream American cultural value system and move away from the Black cultural value system. Newer versions of the theory have given up the idea that black acculturation involves the complete replacement of black cultural identity and values with white cultural identity and values. Instead, Blacks' acculturation is now thought to be characterized by a synthesis of the different cultures and flexibility in movement between cultural worlds (Williams \& Tharp, 2001).

Building on this theoretical perspective, as well as research suggesting that higher SES increases Blacks’ contact with Whites (Iceland and Wilkes 2006), acceptance by Whites (Westie and Westie 1957), acceptance of Whites (Pavlak 1973), and use of social class more than race to define themselves (Weeks and Lupfer 2004), we argue that as Blacks achieve higher incomes and educations they increasingly see the White middle and upper classes as relevant reference groups, which in turn should increase Black's awareness of white tipping norms and reduce black-White differences in normative beliefs. This expectation is tested in a re-analysis of two studies by Lynn (2004, 2006b). Lynn (2004, 2006b) commissioned TNS Intersearch to conduct two national telephone surveys on knowledge about the 15 to 20\% restaurant tipping norm. He found that Blacks were much less familiar with the norm than were Whites even after 
controlling for indicators of socio-economic status such as education and income.

Specifically, in response to an open ended query about the customary restaurant tip, Blacks were less likely than Whites to give a response categorized as " 15 to 20 percent." However, Lynn (2004a, 2006) did not test the moderating effects of socio-economic status on this race difference in norm familiarity. That interaction is examined in a reanalysis of the two data sets below.

\section{METHOD}

TNS Intersearch conducted two national telephone surveys using Genesys random-digit dial sampling. Refusal rates for the two surveys were 71 and 73 percent. Datum from the 1,577 white and 177 black respondents to these two surveys were combined into one data set for this re-analysis.[Note: The racial disparity in sample size reflects the relative sizes of the two groups in the population. Such unequal cell sizes reduce statistical power, but do not otherwise bias the types of regression analyses we report.]

\section{$\underline{\text { Dependent Variables }}$}

Respondents to these surveys were asked essentially the same question worded in two different ways. One survey asked respondents: “Thinking about tipping overall, not your own practices, how much is it customary for people in the United States to tip waiters and waitresses?” The other survey asked respondents: “Thinking about restaurant tipping norms, how much are people in the United Sates expected to tip waiters and waitresses?” Responses to these open-ended questions were categorized into predetermined categories 
(e.g., “15 to 20 percent”) and recorded by the interviewers so coding reliability could not be assessed (see Lynn, 2004a, 2006, for details). For this analysis, the original coding categories were collapsed into two binomial measures of knowledge about the restaurant tipping norm: partial knowledge of the percentage tipping norm (i.e, that it is customary to tip some percentage of the bill: yes $=1$, no $=0$ ) and complete knowledge of the percentage tipping norm (i.e., that it customary to tip 15 to $20 \%$ : yes $=1$, no $=0$ ). $\underline{\text { Independent Variables }}$

In addition to the tipping question, respondents were asked to indicate their: (1) household income (on a 9-point ordinal scale ranging from $10=$ less than $\$ 12,000$ to 100 $=\$ 100,000$ or more), (2) education (on a 7 point ordinal scale ranging from $1=8^{\text {th }}$ grade or less to 7 = postgraduate), and (3) ethnicity (White=1, Black=2). Income and education, which were positively correlated with one another $(r=.38, n=1465, p<.001)$, were each standardized and then averaged to form an index of socio-economic status. In cases where education or income was missing but not the other, the value that was available was used in the index.

\section{RESULTS}

Although logistic regression is typically used when analyzing binomial dependent variables, interaction coefficients and associated statistical tests in logistic regression "do not properly reflect moderation effects in the original data” (Hess, Hu \& Blair, 2010, pg. 3; also see Ai \& Norton, 2003). Therefore, the dependent variables in this study were analyzed using ordinary least squares regression with heteroskedasticity robust standard errors as advocated by Wooldridge (2000). The analysis was hierarchical, with the dependent variable regressed on study, SES, and race in Stage 1. Then the two-way 
interactions between these variables were added in Stage 2. Finally, the three-way interaction between the variables was added in Stage 3 (see Table 1).

Insert Table 1 about here

Consistent with the analyses of this data reported by Lynn (2004a, 2006), Blacks and lower SES respondents had less knowledge (both partial and complete) of the 15 to 20 percent restaurant tipping norm than did Whites and higher SES respondents (see Table 1). There were no main effects of study and only one statistically significant interaction involving study, which indicated that the Black-White difference in partial norm knowledge was smaller in Study 2 than in Study $1(\mathrm{~B}=.14$, t $(1705)=2.19, \mathrm{p}<$ .03). Most important for current purposes is the race $\mathrm{x}$ SES interaction which is tested here for the first time. For partial knowledge of the percentage tipping norm, this interaction was significant and in the expected direction $(\mathrm{B}=.14, \mathrm{t}(1712)=3.88, \mathrm{p}<$ .001). Black-White differences in knowledge that is customary to tip some percentage of the bill were smaller the greater the respondents' socio-economic status (see Figure 1). For complete knowledge of the 15 to 20 percent restaurant tipping norm, this interaction was not significant $(\mathrm{B}=.04, \mathrm{t}(1712)=.72, \mathrm{p}<.47)$. In contrast to partial norm knowledge, Black-White differences in knowledge that it customary to tip 15 to 20 percent of the bill in restaurants was unrelated to the respondents' socio-economic status (see Figure 2). 
Insert Figures 1 and 2 about here

\section{DISCUSSION}

A re-analysis of two national telephone surveys found that black-white differences in awareness that it is customary to tip a percentage of the bill declined as socio-economic status increased. However, black-white differences in awareness that is customary to tip 15 to 20 percent in restaurants were unrelated to socio-economic status. These findings are consistent with theories of SES effects on black acculturation; suggesting that movement up the socio-economic ladder increases Blacks’ involvement with and knowledge of white cultural norms (Frazier, 1958; Williams \& Tharp, 2001). However, they also indicate that this assimilation is far from complete - Blacks' awareness of at least some aspects of white cultural norms remains lower than that of Whites even as SES increases.

On a practical level, the current results suggest that black-white differences in the tendency to base tips on a percentage of the bill may decrease with movement up the socio-economic, but black-white differences in tip size among percentage tippers are unlikely to appreciably diminish with movement up the socio-economic ladder. Thus, restaurant servers and their managers can expect below average tips from black customers regardless of their social class. Furthermore, advocates of campaigns to educate Blacks about the restaurant tipping norm as a means of reducing black-white differences in tipping behavior (see Amer, 2002; Lynn, 2011; Wallace, 2008) probably need to include upper-class Blacks in the target market for those campaigns. 
The current results also raise an interesting question, namely "How do Blacks learn about a percentage tipping norm without learning about the specific normative percentages?” The fact that people tip a percentage of the bill in restaurants cannot be directly observed, so Blacks have to learn about this aspect of the restaurant tipping norm from hearing or reading about it. Since both oral and written communications about the restaurant tipping norm are likely to specify the specific percentages called for by the norm, either many middle and upper class Blacks are consulting sources that are incorrect or they are hearing/seeing but forgetting the correct percentages. Perhaps middle and upper class Blacks feel more comfortable seeking information about, and thereby exposing their ignorance of, White tipping norms from other Blacks than from Whites. If so, then middle and upper-class Blacks’ misconceptions about the normative tip percentages in restaurants could be an example of the blind leading the blind.

Alternatively, many middle and upper-class Blacks may consult written or other sources that inform them about the 15 to $20 \%$ restaurant tipping norm, but ultimately fail to remember the exact percentages because they reject those percentages as ridiculously high. Future research should test these, and perhaps other, potential explanations for the puzzling finding that SES decreases black-white differences in knowledge that it is customary to tip a percentage of bill but not black-white differences in knowledge that it is customary to tip 15 to 20 percent of the bill.

On a more general level, the current findings point to gaps in our knowledge about the processes by which people come to learn about the behavioral norms of their reference groups - especially when those norms are not directly observable. What sources do people consult to learn about reference group behavior and what variables 
affect their choices of sources? How do people evaluate their reference groups' behavior, what factors affect those evaluations, and what happens when the behavior of a reference group is disliked or rejected? Pursuing these lines of inquiry is another potentially interesting direction for future research to take. 


\section{REFERENCES}

Ai, C. \& Norton, E. (2003). Interaction terms in logit and probit models. Economic Letters, 80, 123-129.

Amer, S. (2002). Minority report. Restaurant Business, November 15, 27-38.

Azar, O.H. \& Tobol, Y. (2008). Tipping as a strategic investment in service quality: An optimal-control analysis of repeated interactions in the service industry. Southern Economic Journal, 75, 246-260.

Conlin, M., Lynn, M. \& O’Donoghue, T. (2003). The norm of restaurant tipping. Journal of Economic Behavior and Organization, 52, 297-321.

Frazier, E. F. (1957). The Black Bourgeoisie, New York: Free Press.

Hess, J., Hu, Y. \& Blair, E. (2010). On testing moderation effects in experiments using logistic regression. http://www.bauer.uh.edu/jhess/papers.asp. (accessed July 27, 2011).

Iceland, J. \& Wilkes, R. (2006). Does socioeconomic status matter? Race, class and residential segregation. Social Problems, 52 (2), 248-273.

Lynn, M. (2004). Ethnic differences in tipping: A matter of familiarity with tipping norms. Cornell Hotel and Restaurant Administration Quarterly, 45, 12 - 22.

Lynn, M. (2006a). Tipping in restaurants and around the globe: An interdisciplinary review. In M. Altman (Ed.) Handbook of Contemporary Behavioral Economics: Foundations and Developments, M.E. Sharpe Publishers, 626-643.

Lynn, M. (2006b). Geo-demographic differences in knowledge about the restaurant tipping norm. Journal of Applied Social Psychology, 36, 740-750.

Lynn, M. (2011). Race differences in tipping: Testing the role of norm familiarity. Cornell Hospitality Quarterly, 52 (1), 73-80. 
Pavlak, T. (1973). Social class, ethnicity, and racial prejudice. Public Opinion Quarterly, 37 (2), 225-231.

Star, N. (1988). The International Guide to Tipping, New York: Berkley Books.

Wallace, L. (2008). The tipping gamble: Good service today, insults tomorrow. http://tristatedefenderonline.com/articlelive/articles/2728/1/The-Tipping-Gamble-Goodservice-today-insults-tommorrow/Page1.html (accessed Sept. 5, 2011).

Weeks, M. \& Lupfer, M. (2004). Complicating race: The relationship between prejudice, race, and social class categorizations. Personality and Social Psychology Bulletin, 30, 972-984.

Westie, F. \& Westie, M. (1957). The social distance pyramid: relations between caste and class. American Journal of Sociology, 63, 190-196.

Williams, J.D. \& Tharp, M. (2001). African Americans: Ethnic roots, cultural diversity. In M. Tharp (Ed.), Marketing and Consumer Identity in Multicultural America, Thousand Oaks, CA: Sage, 165-211.

Wooldridge, J. (2000). Introductory Econometrics: A Modern Approach, South-Western College Publishing. 
Table 1. Coefficients and heteroskedasticity robust standard errors from hierarchical regressions of partial and complete norm knowledge on study, race, SES and their interactions.

\begin{tabular}{lll}
\hline Variable & Partial Norm Knowledge & Complete Norm Knowledge \\
\hline Stage 1 & $.93^{* * *}$ & $.71^{* * *}$ \\
Intercept & $(.02)$ & $(.03)$ \\
& -.00 & .00 \\
Study & $(.01)$ & $(.02)$ \\
& $-.15^{* * *}$ & $-.30^{* * *}$ \\
Race $(\mathrm{W}=0, \mathrm{~B}=1)$ & $(.03)$ & $(.04)$ \\
& $.08^{* * *}$ & $.16^{* * *}$ \\
SES & $(.01)$ & $(.01)$ \\
& & .04 \\
Stage 2 & $.14^{* * *}$ & $(.05)$ \\
Race x SES & $(.04)$ & .02 \\
& .01 & $(.02)$ \\
SES x Study & $(.02)$ & -.02 \\
Race x Study & $.14 *$ & $(.08)$ \\
Stage 3 & $(.06)$ & -.15 \\
Race x SES x Study & -.09 & $(.10)$ \\
\hline$* \mathrm{p}<.05, * * \mathrm{p}<.01, * * * \mathrm{p}<.001$ & \\
\hline
\end{tabular}




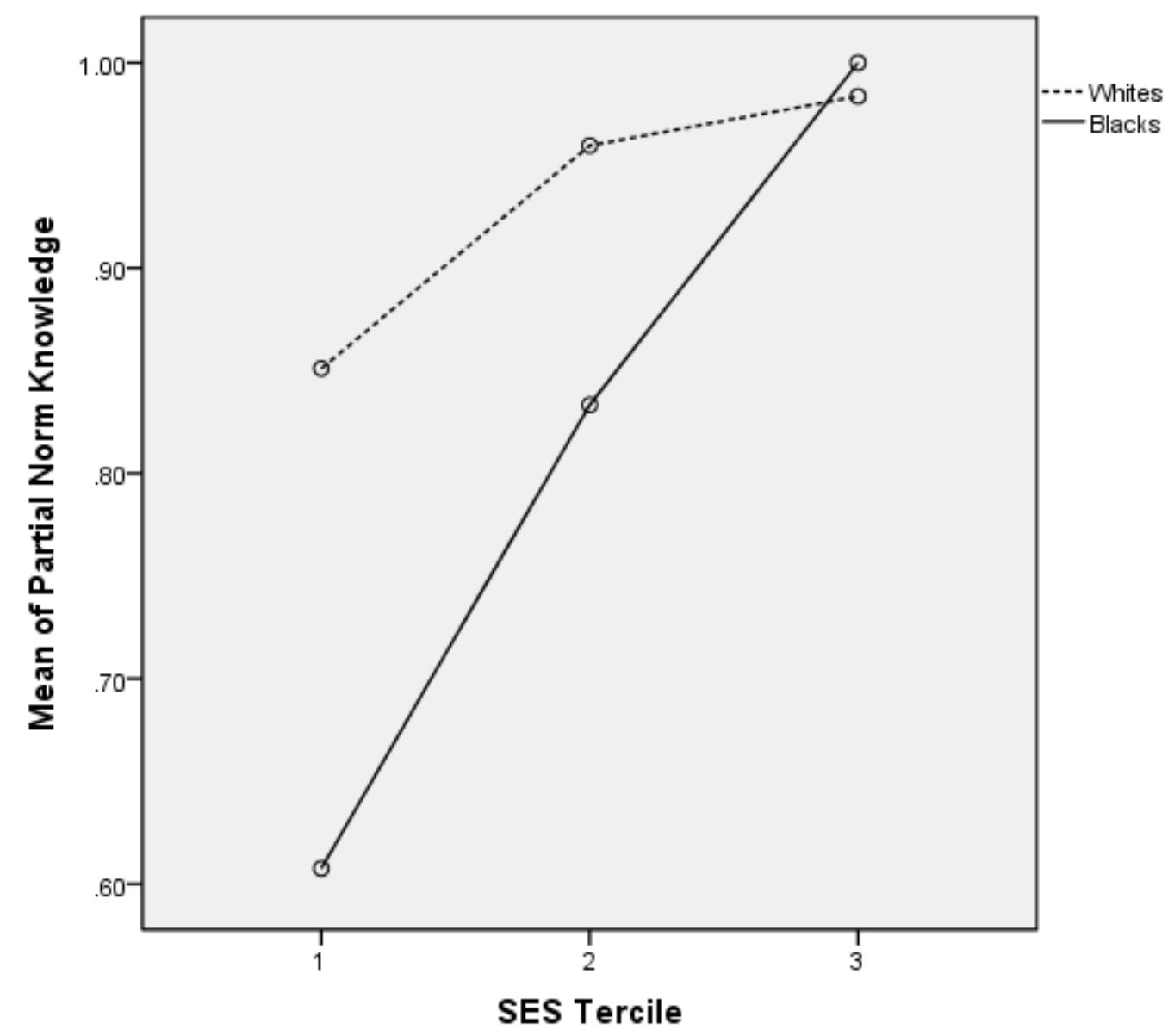

Figure 1. The race by SES interaction effect on knowledge that it is customary to tip a percentage of the bill in restaurants. [Note: Although the graph shows SES broken down into terciles, it was treated as a continuous variable in the regression analyses.] 


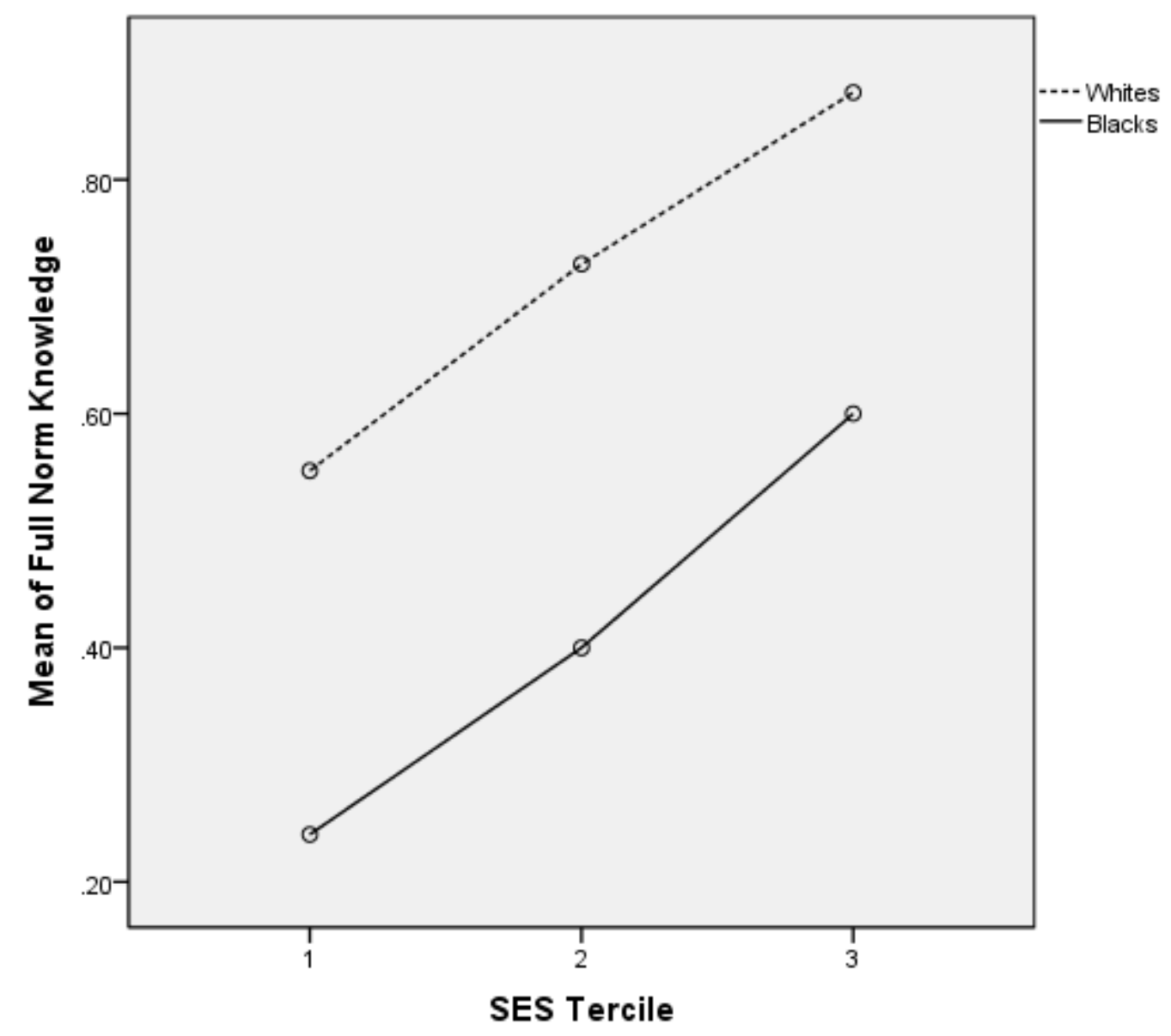

Figure 2. The race by SES interaction effect on knowledge that it is customary to tip 15 to 20 percent of the bill in restaurants. [Note: Although the graph shows SES broken down into terciles, it was treated as a continuous variable in the regression analyses.] 